\title{
Comparative analysis of the Allam cycle and the cycle of compressorless combined cycle gas turbine unit
}

\author{
Mikhail Sinkevich ${ }^{1,2}$, Anatoliy Kosoy ${ }^{1,3}$ and Oleg Popel ${ }^{1}$ \\ ${ }^{1}$ Joint Institute for High Temperatures of the Russian Academy of Sciences, Izhorskaya St., Bldg. 13, Block 2, Moscow, Russia \\ ${ }^{2}$ Peoples' Friendship University of Russia (RUDN University), Miklukho-Maklaya str., Bldg. 6, Moscow, Russia \\ ${ }^{3}$ Moscow Power Engineering Institute, Krasnokazarmennaya str., Bldg. 14, Moscow, Russia
}

\begin{abstract}
Nowadays, alternative thermodynamic cycles are actively studied. They allow to remove $\mathrm{CO} 2$, formed as a result of fuel combustion, from a cycle without significant energy costs. Calculations have shown that such cycles may meet or exceed the most advanced power plants in terms of heat efficiency. The Allam cycle is recognized as one of the best alternative cycles for the production of electricity. Nevertheless, a cycle of compressorless combined cycle gas turbine (CCGT) unit is seemed more promising for cogeneration of electricity and heat. A comparative analysis of the thermal efficiency of these two cycles was performed. Particular attention was paid to ensuring equal conditions for comparison. The cycle of compressorless CCGT unit was as close as possible to the Allam cycle due to the choice of parameters. The processes, in which the difference remained, were analysed. Thereafter, an analysis of how close the parameters, adopted for comparison, to optimal for the compressorless CCGT unit cycle was made. This analysis showed that these two cycles are quite close only for the production of electricity. The Allam cycle has some superiority but not indisputable. However, if cogeneration of electricity and heat is considered, the thermal efficiency of the cycle of compressorless CCGT unit will be significantly higher. Since it allows to independently regulate a number of parameters, on which the electric power, the ratio of electric and thermal power, the temperature of a working fluid at the turbine inlet depend. Thus, the optimal parameters of the thermodynamic cycle can be obtained in a wide range of operating modes of the unit with different ratios of thermal and eclectic powers. Therefore, the compressorless CCGT unit can significantly surpass the best steam turbine and combined cycle gas turbine plants in district heating system in terms of thermal efficiency.
\end{abstract}

\section{Introduction}

Recently, alternative thermodynamic cycles are actively investigated, permitting, without significant energy costs, to remove $\mathrm{CO}_{2}$, formed as a result of fuel combustion [1-4], from the cycle. Calculations have shown that such cycles may not be inferior to the most advanced power plants with regard to thermal efficiency [4]. The Allam cycle is considered as one of the best for the production of electricity [5]. The construction of power development plant with a capacity of $50 \mathrm{MW}$ is already underway with using this cycle [4]. However, the cycle of compressorless combined cycle gas turbine (CCGT) unit is seemed more promising for cogeneration of electricity and heat [6-8].

When new cycles are studied, researchers have to make many assumptions, accepted based on existing experience. However, they need to be verified experimentally. Such assumptions include the attainable standard of efficiency for individual parts of a power plant, implementing a cycle, and an achievable temperature level.
In various studies, these accepted assumptions may differ significantly. So, in some studies, for example, the turbine inlet temperature is taken to be very moderate, up to $1200 \mathrm{~K}$ [1], in other works, it is considered the temperature almost equal to $1700 \mathrm{~K}$ [2]. The most realistic temperature is $1400 \mathrm{~K}$ [4]. The effectiveness of individual parts of the researched cycles can also differ considerably. If the different cycles are compared by the resulting indicators, obtained in different studies, the problem of separation causes of the variance in the compared indicators arises. This difference is either a consequence of the advantages and disadvantages of the compared cycles, or it is a reflection of the optimism or pessimism of researchers, performed a work.

\section{The Aim of Research}

The main goal of the study is an objective comparative assessment of the thermal efficiency of two new promising thermodynamic cycles, which have a rather important advantage - removing $\mathrm{CO}_{2}$, resulting from 
the combustion of fuel, from the cycle in the form of a pure substance.

\section{Description of the compared cycles}

A compressorless combined cycle gas turbine unit schematic is shown in Fig. 1. Conventionally, the beginning of a thermodynamic cycle may be associated with a moment when all components of a working fluid are being in a liquid phase. Feeding pumps for fuel 1 , oxygen 2 , carbon dioxide 3 , and water 4 are used to increase their pressure. The fuel pump controls the fuel supply. After the fuel pump, the fuel is fed sequentially to a cold utilizer of liquefied natural gas (LNG) 5 (it is supposed to use LNG as the fuel) and a fuel heater 6 . And after that, the heated fuel enters the primary zone of a combustion chamber 7 . The oxygen supply is regulated by the oxygen pump. Thereafter, oxygen first enters an oxygen cold utilizer 8 . Then it goes into an oxygen heater 9 , after which the heated oxygen enters the primary zone of the combustion chamber. The carbon dioxide pump controls $\mathrm{CO}_{2}$ supply. After the carbon dioxide pump, $\mathrm{CO}_{2}$ first enters a heater 10 , and then goes to a recuperative heat exchanger 11. Heated $\mathrm{CO}_{2}$ is supplied to the primary and secondary zones of the combustion chamber simultaneously so as to ensure an acceptable quality of fuel combustion and the required temperature field at the combustion chamber outlet. A small fraction of $\mathrm{CO}_{2}$ is used to cool the hot parts in a combined cycle gas turbine flow part 12 . The exchanger 13, and then, as well as $\mathrm{CO}_{2}, \mathrm{H}_{2} \mathrm{O}$ enters the primary and secondary zones of the combustion chamber. Thus, fuel is supplied to the combustion chamber in an amount that provides thermal and electrical load coverage. The oxygen supply is regulated so that there is a minimum excess of oxygen, providing the required combustion efficiency. The $\mathrm{CO}_{2}$ supply maintains a predetermined temperature of the working fluid in the turbine (depending on the control mode at the inlet or outlet). The supply of $\mathrm{H}_{2} \mathrm{O}$ regulates the ratio of the generated heat and electric energy. A mixture of combustion products and ballasting components with a predetermined temperature, obtained in the combustion chamber, represents the working fluid at the combined cycle gas turbine inlet 12 . The working fluid expands in the combined cycle turbine, doing work. The performed work is converted into electricity by a generator 14 . The working fluid, having spent in the turbine, is sent to the recuperative heat exchangers 11 and 13 which heat up the ballasting components $\mathrm{H}_{2} \mathrm{O}$ and $\mathrm{CO}_{2}$. In recuperative heat exchangers, the working fluid is cooled to a temperature as close as possible to the dew point temperature when $\mathrm{H}_{2} \mathrm{O}$, being part of the working fluid mixture, begins to condense. Thereafter, the working fluid is directed to a low pressure contact condenser 15 which has two sections, located one above the other. Water is supplied in a first section 16 for cooling the working fluid with a temperature slightly higher than the temperature of return system water. Cooling water, with a temperature slightly

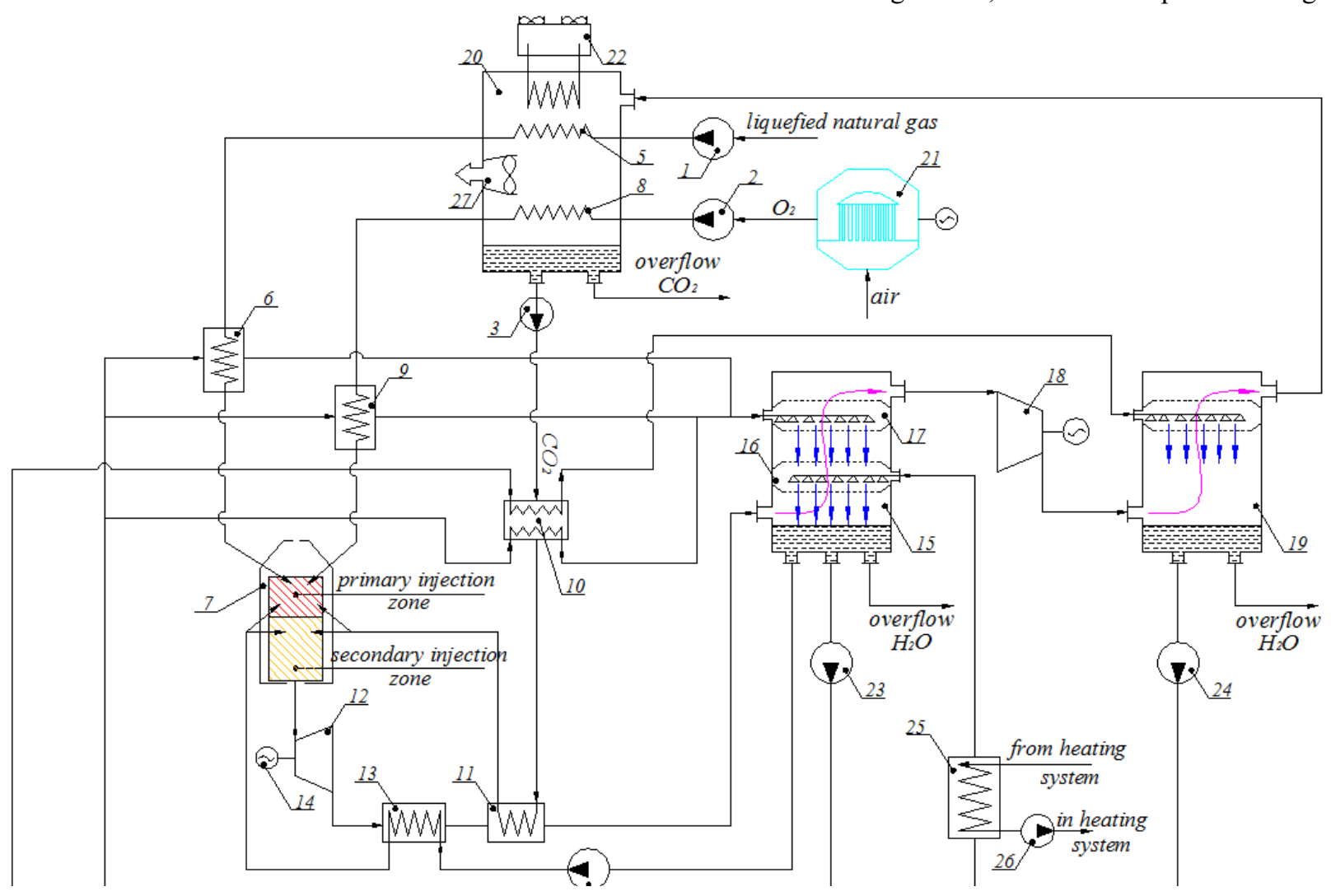

Fig. 1. Compressorless combined cycle gas turbine unit schematic. 
in a second section 17. At the low pressure contact condenser outlet, the working fluid is carbon dioxide with small contaminants, including a small amount of remained $\mathrm{H}_{2} \mathrm{O}$. Therefore, the pressure of the working fluid is increased by a $\mathrm{CO}_{2}$ compressor 18 to $3,5 \mathrm{MPa}$ in order to avoid freezing (the pressure at which the condensation temperature of $\mathrm{CO}_{2}$ is higher than the freezing temperature of $\mathrm{H}_{2} \mathrm{O}$ ). After that, the $\mathrm{H}_{2} \mathrm{O}$ residues are condensed in a high pressure contact condenser 19. The working fluid, cooled in this contact condenser, is sent to a liquefier of $\mathrm{CO}_{2} 20$. The cold of liquid oxygen from an air separation unit (ASU) 21 and cold of liquid oil are used to liquefy the $\mathrm{CO}_{2}$. The liquefier of $\mathrm{CO}_{2}$ includes the utilizer of liquid oxygen cold 8 and the CNG cold utilizer 5 for this purpose. The entire shortage of cold, required to liquefy $\mathrm{CO}_{2}$, is compensated by a refrigeration unit 22 . Each contact condenser has its own circuit of circulating water. Circulation pumps 23 and 24 take in water from the contact condenser water tanks. The water is divided into several streams after the circulation pump 23 in the circulation circuit of the low pressure condenser. Most of the water goes to a heater of network water 25 after which it returns to the first section of the low pressure condenser. The remaining water is supplied in parallel streams to the fuel heater 6 , the oxygen heater 9 and the $\mathrm{CO}_{2}$ heater 10. Having released the heat in the heaters, the cooled water returns to the second section of the low pressure contact condenser. After the pump 24, the circulation water of the high pressure condenser is supplied to the $\mathrm{CO}_{2}$ heater 10. It is designed so that two heating fluids are used for heating up. After the heater, this water returns to the high pressure contact condenser 19. The return network water is supplied to the network water heater 25 . After that, water is heated to the temperature, required by a temperature graph, and returned to the heat network by a network water pump 26. Liquid oxygen is produced in the cryogenic air separation unit 21. The liquefier of $\mathrm{CO}_{2} 20$ is equipped with a system for removing non-condensable gases and collecting an excess of liquid $\mathrm{CO}_{2}$. In addition, the selection of excess $\mathrm{H}_{2} \mathrm{O}$ is provided.

A detailed description of the Allam cycle is given in [4]. A diagram in pressure - enthalpy coordinates, conventionally assigned to pure carbon dioxide (Fig.2.), is also shows there.

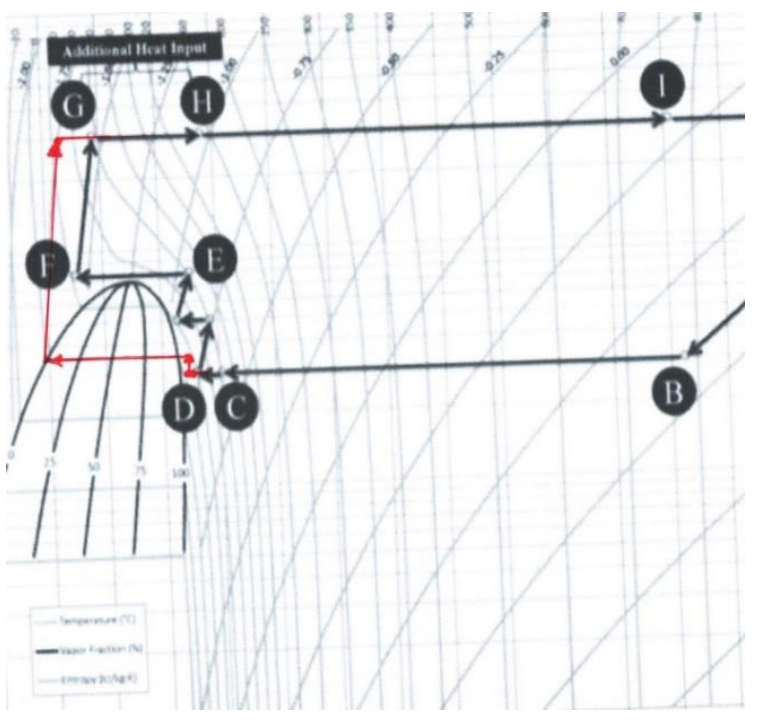

Fig. 2. Image of the Allam cycle in diagram P-I for carbon dioxide [4].

The working fluid is fed into a turbine (at point A) with a pressure of $30 \mathrm{MPa}(300 \mathrm{bar})$ and a temperature of $1323 \mathrm{~K}\left(1150{ }^{\circ} \mathrm{C}\right)$. The expansion process in the turbine is shown by line A-B. A pressure is equal to 3 $\mathrm{MPa}(30 \mathrm{bar})$ and a temperature is $1000 \mathrm{~K}\left(727^{\circ} \mathrm{C}\right)$ at the turbine outlet. After expansion in the turbine, the working fluid is sent to a recuperator where it is cooled, heating the recirculating flow of supercritical $\mathrm{CO} 2$ (line $\mathrm{B}-\mathrm{C}$ ). The working fluid is cooled to $333 \mathrm{~K}$ $\left(60{ }^{\circ} \mathrm{C}\right)$ in the recuperator. Further cooling of the working fluid is carried out by removing heat into the environment (line C-D). The pressure increase of the working fluid (recirculating gas) is performed in several stages with intermediate cooling between them (line D-E-F-G). The working fluid has a pressure of 30 $\mathrm{MPa}(300 \mathrm{bar})$ and a temperature of $333 \mathrm{~K}\left(60^{\circ} \mathrm{C}\right)$ at the end of the pressure increase process (at point I). The working fluid is heated (line G-H-I) to $990 \mathrm{~K}$ (717 ${ }^{\circ} \mathrm{C}$ ) before feeding into a combustion chamber. Most of the heat (equivalent length H-I) occurs due to the heat, transferred in a heat exchanger. Gases have very high heat capacity in the supercritical state at temperatures close to critical. Thus, there is not enough recuperative heat and a deficit of low temperature heat is formed. It is proposed to compensate for this deficit by external sources of low temperature heat (equivalent segment $\mathrm{G}-\mathrm{H})$. As an example, heat recovery of ASU is considered.

\section{Results of comparison}

The supply of $\mathrm{H}_{2} \mathrm{O}$ to the combustion chamber in the cycle of compressorless CCGT unit is regulated and can be equal to zero in the limit. If the same parameters as in the Allam cycle at the turbine inlet are taken, for example, the degree of expansion in the turbine, the adiabatic efficiency of the turbine, hydraulic losses along the path, and the efficiency of the recuperator, then the series of reference points of these two cycles will coincide (Fig. 2). A part of a diagram at an 
enlarged scale, where these cycles differ, is shown in Fig. 3.

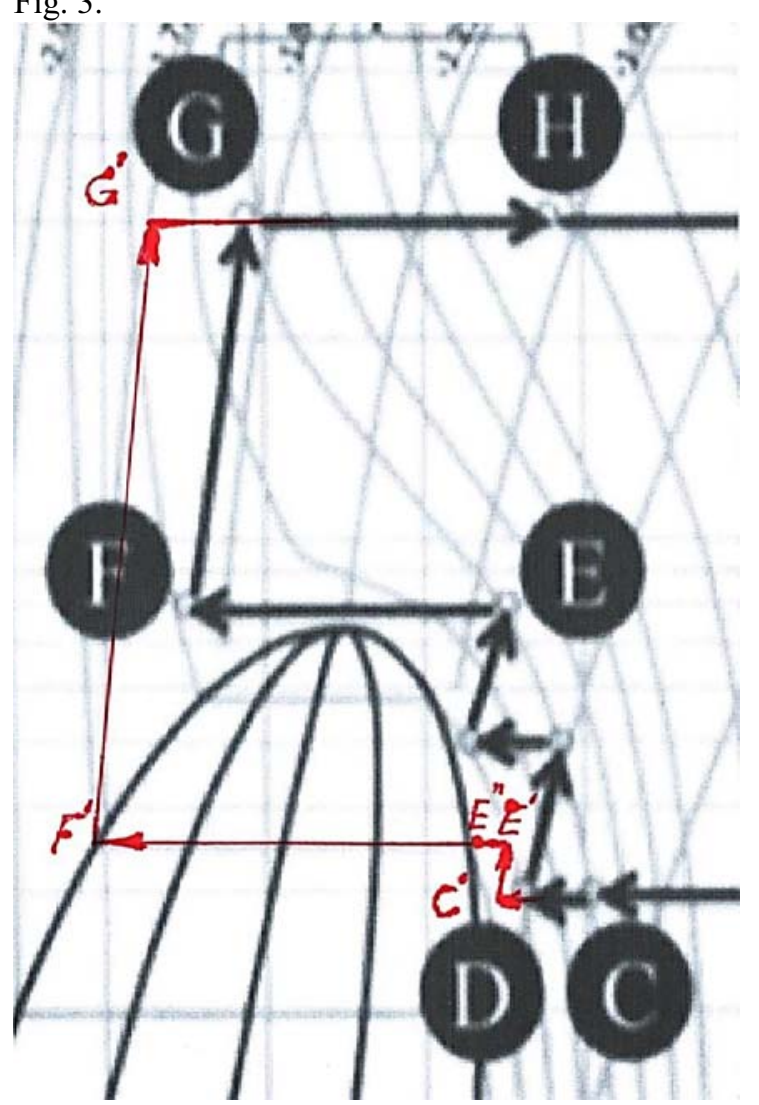

Fig. 3. Comparison of the Allam cycle with the cycle of compressorless CCGT unit for carbon dioxide in the P-I diagram.

In the cycle of compressorless CCGT unit, the spent working fluid is cooled in the recuperator and then in the contact condenser to a temperature slightly lower than at point D (point C'). At the same time, part of the heat is transferred to the heating system if there is a need for it. The all rest heat is returned to the cycle. After that, the compressor of $\mathrm{CO}_{2}$ raises the pressure to $3,5 \mathrm{MPa}$ (35 bar) so that the condensation temperature of $\mathrm{CO}_{2}$ is slightly higher than $273 \mathrm{~K}\left(0^{\circ} \mathrm{C}\right)$ and there is no frosting of the heat exchange surfaces (point $\mathrm{E}^{\prime}$ ). After that, another part of the heat is returned to the cycle in the high pressure contact condenser (line E'E'). The liquefaction of $\mathrm{CO}_{2}$ (line E' '-F') is carried out at the temperature slightly higher than $273 \mathrm{~K}\left(0{ }^{\circ} \mathrm{C}\right)$. The heat of condensation is partially utilized for heating up the fuel and oxygen. The remaining share of the condensation heat of $\mathrm{CO}_{2}$ is removed to the atmosphere. If the conditions for comparison with the ambient temperature equal to $288 \mathrm{~K}\left(15{ }^{\circ} \mathrm{C}\right)$ are accepted, then an additional refrigeration cycle will be required to remove heat. The pressure of liquid $\mathrm{CO}_{2}$ is increased by the pump (line F'-G'). The temperature at point $G^{\prime}$ is almost lower than $40 \mathrm{~K}$ at point $\mathrm{G}$. However, heating from point $G^{\prime}$ to point $G$ is produced by cooling of the spent working fluid (lines C-C' and E'-E'). Thus, two analysed cycles are completely identical at the region G-H-I-A-B-C.
For comparison the thermodynamic efficiency of processes it is more evident to present diagrams in the coordinates of temperature-entropy. The compared processes in the temperature - entropy coordinates is shown in Fig. 4.

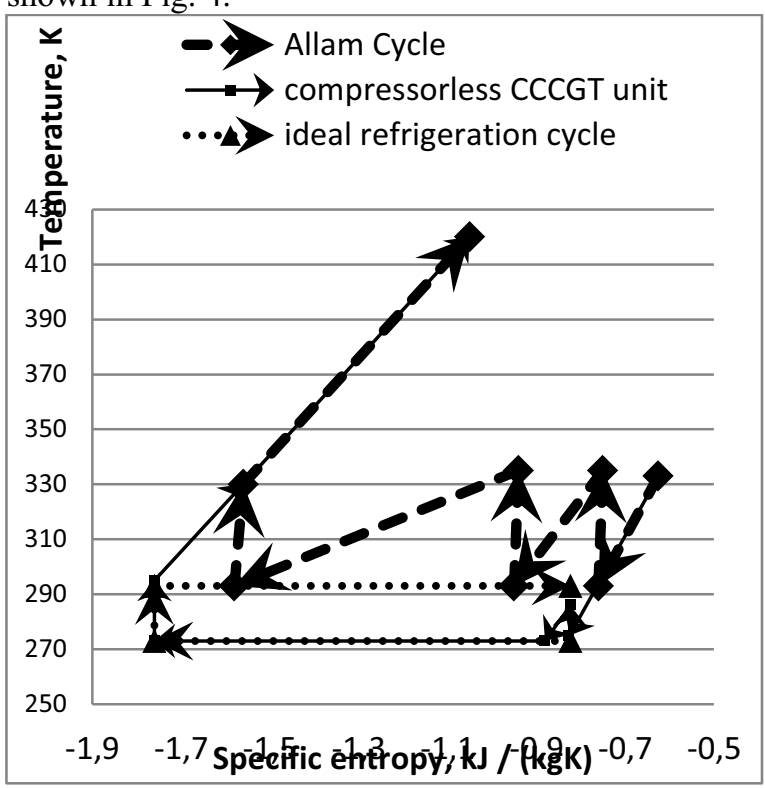

Fig. 4. Comparison of the Allam cycle with the cycle of compressorless CCGT unit in the T-S coordinates.

In the Allam cycle the average temperature of heat dissipation is approximately $313 \mathrm{~K}\left(40{ }^{\circ} \mathrm{C}\right)$. The average temperature of heat removal can be somewhat lower due to the choice of an effective working fluid for the refrigeration cycle. In addition, if the processes are idealized (for example, it is assumed that the refrigeration cycle is the ideal Carnot cycle, and the temperature head of heat transfer to the refrigeration cycle is equal to zero), then the cycle of compressorless CCGT unit will be somewhat more efficient than the Allam cycle. However, the Allam cycle can slightly exceed the cycle of compressorless CCGT unit in real thermodynamic processes. All depend on how effective the refrigeration cycle will be and what temperature head will be when removing heat to the refrigeration cycle. The temperature of heat removal from the cycle determines the work that will be spent on increasing the pressure of the working fluid (the work, having spent on the drive of the refrigeration machine, is one of the components of the work, spent on increasing the pressure of the working fluid). Calculations show that the work, spent on increasing the pressure of the working fluid, is $10,5 \%$ of the higher calorific value of the fuel [4]. Consequently, a ten percent difference in the efficiency of the cooling and pressure increase processes will lead to a difference in the efficiency of the cycles as a whole by only one percent.

With the small and not indisputable advantages of the Allam cycle for producing only electricity, this cycle is not suitable for cogeneration of electricity and heat. This cycle is characterized by a deficit of low temperature heat. For covering of which, it is still necessary to find a source of such heat. Thus, there is no need to talk about the release of low temperature 
thermal energy as a commercial product. In the cycle of compressorless CCGT unit, it is possible to adjust the ratio of recirculating $\mathrm{CO}_{2} / \mathrm{H}_{2} \mathrm{O}$. An increase in the amount of $\mathrm{H}_{2} \mathrm{O}$, supplied to the combustion chamber, negatively affects the efficiency of electric power generation. This occurs for two reasons in terms of a thermodynamic point of view. Firstly, the average temperature of heat input in the combustion chamber decreases (the temperature of the working component decreases before the supply to the combustion chamber). Secondly, the average temperature of heat removal from the cycle increases. However, the average temperature of heat removal is part of the removed heat. In addition, all the removed heat is transferred to the heating system in the form of commodity output when a ratio $\mathrm{CO}_{2} / \mathrm{H}_{2} \mathrm{O}<1$. The cooling process of the spent working fluid and heating of the working components before feeding into the combustion chamber at various ratios of recirculating $\mathrm{CO}_{2} / \mathrm{H}_{2} \mathrm{O}$ is shown in Fig. 5 in T-S coordinates.
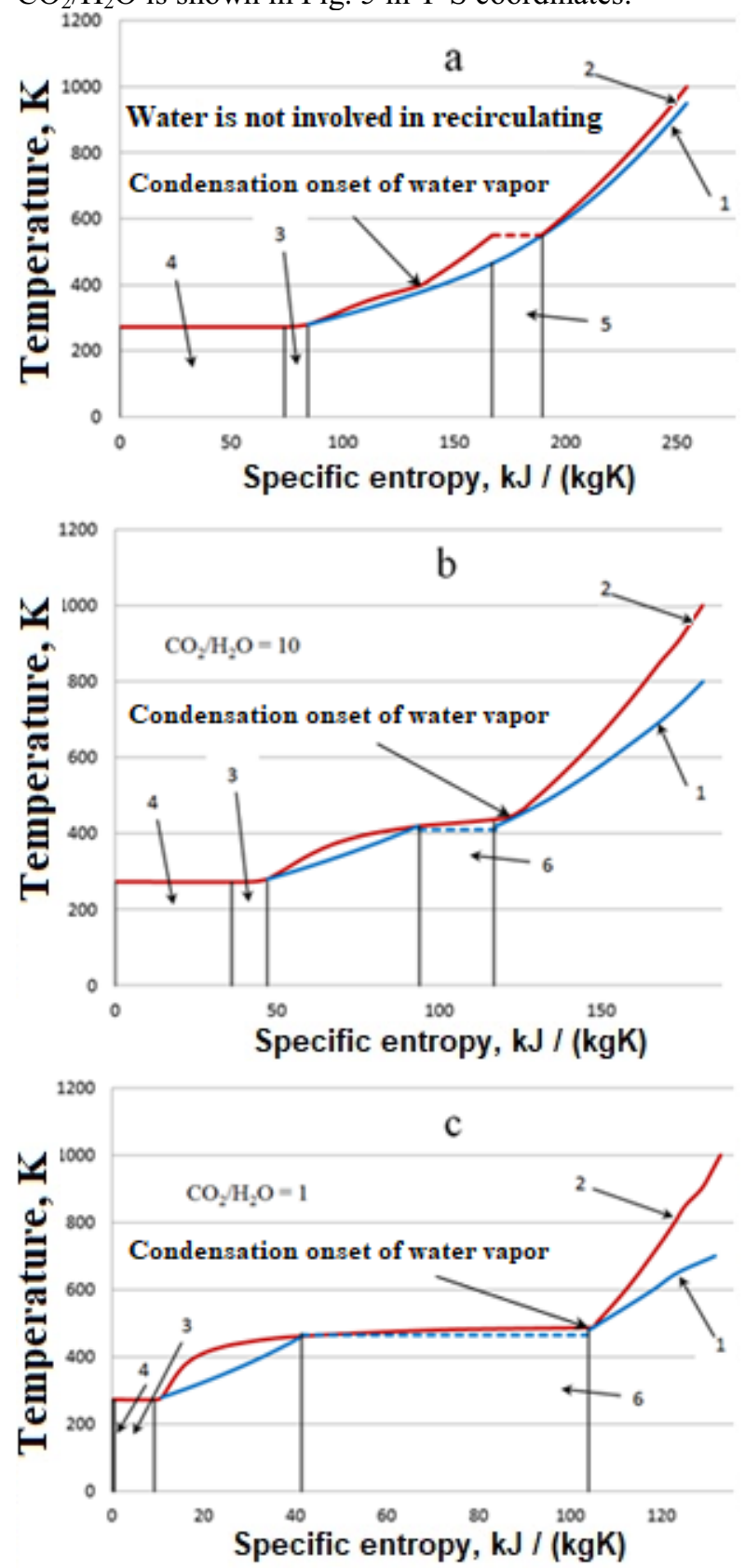

Fig. 5. The cooling process of the spent working fluid in T-S coordinates: 1 - heating line of the working fluid components before feeding into the combustion chamber; 2 - cooling line of the spent working fluid; 3 - heat for heating fuel and oxygen to a temperature of $\mathrm{CO}_{2}$ condensation; 4 - heat transfer into the environment; 5 - heat, supplied from an external low temperature heat source; 6 - heat, given off to the heating system.

Entropies in specific units are given. However, considering the composition and quantity of the working fluid differ at various points of the cycle, all entropies are assigned to one kilogram of fuel. The reference points for heating and heated flows were selected so that the minimum temperature head, which is necessary for heat transfer, is provided everywhere. If the heat is removed from the cycle somewhere, the reference points are adjusted accordingly. When only $\mathrm{CO}_{2}$ is used for recycling (Fig. 5a), in order to ensure the maximum temperature of the working fluid components before feeding into the combustion chamber and at the same time not violate the second law of thermodynamics, a certain amount of heat must be supplied to the components of the working fluid in the temperature range of 400-550 K (area 5) from an external low temperature source. ASU can be such source as an option. Part of the spent working fluid heat is diverted to the fuel and oxygen heating to a temperature of $\mathrm{CO}_{2}$ condensation (area 3). In the Allam cycle, the ability to utilize the cold of liquid oxygen and fuel is not mentioned, but for the cycle of compressorless CCGT unit is an essential point. Heat is generally removed from the cycle of compressorless CCGT unit to the environment at a temperature lower than the ambient temperature (area 4). A refrigeration machine is used for this purpose. In addition, the operation of this machine can be reduced because liquid oxygen and LNG have some stock of cold (heat is necessary for heating to the environment), which can be used to liquefy $\mathrm{CO}_{2}$ (area 3 ). The need for heat supply from an external source (area 5) is due to the fact that the total water equivalent of the working fluid components at high pressures in the range of low temperatures significantly higher than the water equivalent of the spent working fluid at these temperatures. And even a small increase in the water equivalent of the spent working fluid, owing to the condensation of water vapor, resulting from the combustion of fuel, cannot compensate for the shortage of low temperature heat. Thus, it is necessary to look for an external source, or all this heat will be compensated by additional fuel. The picture changes significantly when $\mathrm{H}_{2} \mathrm{O}$ is connected to recirculation. Already at a ratio of $\mathrm{CO}_{2} / \mathrm{H}_{2} \mathrm{O}=10$, condensing water vapor increases the water equivalent of the spent working fluid so that a heat surplus with a temperature of $400-450 \mathrm{~K}$ instead of a deficit is obtained (Fig. $5 \mathrm{~b}$ ). This heat can be released into the heat network in the form of commodity output (area 6). At the same time, heat removal to the environment is almost halved. The needs for hot water supply in summertime can be covered with small amounts of recycle $\mathrm{H}_{2} \mathrm{O}$. The heat removal to the environment approaches to the value of 
zero with the ratio $\mathrm{CO}_{2} / \mathrm{H}_{2} \mathrm{O}=1$ (Fig. 5c). The heat network is the cold source for the thermodynamic cycle. Thus, almost all fuel energy (at the higher calorific value) is useful. Only a part of the energy, spent on the station own needs and irretrievable losses during mechanical and electrical energy conversions, is lost. The amount of energy loss can be $5-10 \%$ of the electric power of the station. Such losses correspond to the coefficient of fuel usage, related to the higher calorific value of fuel, equal to $0,94-0,97$. The value will be $1,045-1,08$ if it relates to the lower calorific value it. Calculations showed that $1,46 \mathrm{~kW}$ of heat can be produced at $\mathrm{CO} 2 / \mathrm{H} 2 \mathrm{O}=1$ per $1 \mathrm{~kW}$ of useful electric power, with an efficiency referred to the higher calorific value equal to $0,356(0,396$ attributed to the lower calorific value). Heat efficiency with such indicators at cogeneration of electric and thermal energy will be $10-15 \%$ better than a typical steam turbine CHP plant and 5-10\% better than CCGT-CHP plant [8].

\section{Conclusions}

The analysis showed that the compared cycles have a good potential to achieve high thermal efficiency for the production of electricity, not being inferior to the most advanced technologies. In addition, these two cycles are fairly close for producing only electricity. Some superiority of the Allam cycle can be recognized, but it is not indisputable.

The cycle of compressorless CCGT unit significantly exceeds the Allam cycle for cogeneration of electricity and heat. The compressorless CCGT unit allows to regulate a number of parameters independently, on which the electric power, the ratio of electric and thermal power, the temperature of the working fluid at the turbine inlet depend. Thus, the optimal parameters of the thermodynamic cycle can be obtained in a wide range of operating modes of the installation with different ratios of thermal and eclectic powers. Due to this the compressorless CCGT unit can significantly surpass the best technical steam turbine and combined cycle gas turbine plants in district heating systems in terms of thermal efficiency.

\section{Acknowledgment}

The research was financially supported by the Russian Science Foundation (project № 19-19-00558).

\section{References}

1. Sanz W., Jericha H., Luckel F., Heitmeir F. A further step towards a Graz cycle power plant for CO2 capture //ASME Paper GT2005-68456, ASME Turbo Expo. 2005.

2. Oxy-fuel gas turbine, gas generator and reheat combustor technology development and demonstration / R. Anderson, F. Viteri, R. Hollis et. al. //ASME Paper GT2010- 23001, ASME Turbo Expo. 2010.

3. Yang H. J., Kang D.W., Ahn J.H., Kim T.S. Evaluation of design performance of the semiclosed oxy-fuel combustion combined cycle //Journal of Engineering for Gas Turbines and Power. 2012. Vol. 134. No 11. P. 111702.

4. High efficiency and low cost of electricity generation from fossil fuels while eliminating atmospheric emissions, including carbon dioxide / R.J. Allam, M.R. Palmer, G.W. Brown et. al. // Energy Procedia. 2013. Vol. 37. P. 1135- 1149.

5. Design concept of high-power supercritical CO2 Allam cycle gas turbine flow path /A.N. Rogalev, E.Yu. Grigoryev, V.O. Kindra, S.K. Osipov, S.A. Pavlychev //«Вестник ИГЭУ» Вып. 32018 г. DOI: 10.17588/2072-2672.2018.3.005-014

6. Kosoi A.S., Popel O.S., Sinkevich M.V. METHOD AND PLANT FOR MECHANICAL AND THERMAL ENERGY GENERATION// Patent RU 2651918 C1: 24.04.2018 Bull. № 12. http://www1.fips.ru/wps/PA_FipsPub/res/BULLE TIN/IZPM/2018/04/27/INDEX_RU.HTM

7. A.S. Kosoj, A.A. Kosoj, M.V. Sinkevich, Y.A. Antipov METHOD AND PLANT FOR MECHANICAL AND THERMAL ENERGY GENERATION // Patent RU 2665794 C1: 04.09.2018 Bull. № 25.

8. The Conceptual Process Arrangement of a Steam-Gas Power Plant with Fully Capturing Carbon Dioxide from Combustion Products / A. S. Kosoi, Yu. A. Zeigarnik, O. S. Popel, M. V. Sinkevich, S. P. Filippov, V. Ya. Shterenberg // Thermal Engineering, 2018, Vol. 65, No. 9, pp. 597-605. DOI: 10.1134/S0040601518090045 A. S. Kosoi, Yu. A. Zeigarnik, O. S. Popel et. al., Thermal Engineering, 65(9), 597-605 (2018)

9. Анализ эффективности работы БКПГУ в системах централизованного теплоснабжения / Синкевич М.В., Борисов Ю.А., Косой А.А., Рамазанов Э.Р., Попель О.С. (в печати) 